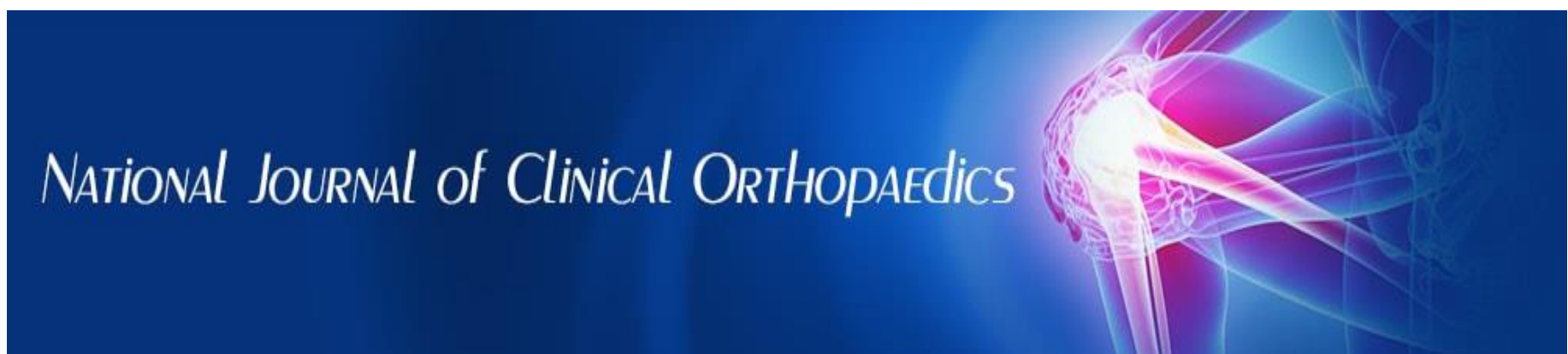

ISSN (P): 2521-3466

ISSN (E): 2521-3474

(C) Clinical Orthopaedics

www.orthoresearchjournal.com

2019; 3(1): 75-78

Received: 01-11-2018

Accepted: 04-12-2018

Dr. Nishant Panegaon

Assistant Professor Department

of Orthopedics, Mahadevappa

Rampure Medical College,

Kalaburagi, Karnataka, India

Dr. Shivabasanagouda Patil Post Graduate Department of Orthopedics, Mahadevappa Rampure Medical College, Kalaburagi, Karnataka, India

\section{Distal radius fracture treated with external fixation: A clinical study}

\section{Dr. Nishant Panegaon and Dr. Shivabasanagouda Patil}

DOI: $\underline{\text { https://doi.org/10.33545/orthor.2019.v3.i1b.16 }}$

\section{Abstract}

Background and objective: Distal radius fractures accounts for almost $10 \%$ of all the fractures. The most commonest cause being fall on outstretched hand. Evidence suggests that good anatomical articular reduction with surgery reduces the complications associated with the fracture, hence the management of fractures have evolved from cast immobilization to operative interventions. Aim of this study was to observe the functional and anatomical outcome of distal radius treated with ligamentotaxis using external fixators.

Materials and Methods: The present study includes 40 cases of distal radius fractures who were operated with external fixation in Basaveshwar Hospital Kalaburagi between Jan 2017 to Dec 2018. Ethical clearance was taken from the ethical committee of the institution and Informed consent were taken from the patients. Frykman's classification was used for the classification of fractures being treated and patients final outcome was measured by Gartland and Werley's Score (demerit system).

Results: The present study includes 40 patients, 24 were male and 16 were female. The mean patient age was 35 years (22yrs-50yrs). Left hand was involved in 24 patients and right hand in 16 patients. The mechanism of injury was road traffic accident in majority. Most of the patients were operated within 3-4 days of injury. 12 patients with high impact type injuries had associated fractures. Most of fractures were of Type III, IV, and V of Frykman's classification of fractures. End Results according to Demerit point system of Gartland and Werley's among 40 patients treated with External fixation were Excellent in 20 patients, Good in 12 patients, Fair in 7 patients, and Poor in 1 patient.

Conclusion: External fixation provides good to excellent results in distal radius fractures and are found to be effective in the correction and maintenance of distal radius anatomy.

Keywords: Distal radius, external fixation, Gartland and werley's score, Frykman's classification

\section{Introduction}

Fractures of the distal radius are the most frequently occuring injuries and account for about $10 \%$ of the fractures in human skeleton ${ }^{[1]}$. These fractures are most commonly caused due to fall on outstretched hand. Clinically the patient complains of pain along with tenderness, bruising, and swelling. It may be associated with deformities like dorsal angulation and distal neurovascular compromise. Distal radial fracture can present in any group of patients with bimodal age and sex distribution. Patho-physiologically, the force is applied longitudinally or obliquely on to the hand and wrist is absorbed by the distal radius because it is the loadbearing bone in the forearm ${ }^{[2,3]}$.

Patients were radiographically investigated using antero-posterior and lateral radiographs. For intra-articular fractures CT scans were done to visualize fragment displacement. Despite the large number of researches done, there is no specific single approach to treat these fractures ${ }^{[4,5]}$. The indication of reductive or operative treatment modalities is highly dependent on the patient's age and level of activity. Among the forms of treatment described are plaster-cast immobilization, use of intra-focal, extra-focal or intramedullary percutaneous Kirschner wires, dorsal and volar plates and external fixation ${ }^{[6,7,8,9]}$.

Locked plate and screw systems function as a single unit for fracture fixation whereas conventional plates require compression between the implant and the bone. As the bone density is compromised in elderly, the locked plate and screw system provides greater rigidity and stabilization when compared to conventional plates. The locked plate-screw mechanism also functions as a substitute for the bone cortex, thus making it possible to use monocortical screws $[10,11,12,13]$.
Dr. Nishant Panegaon Assistant Professor Department of Orthopedics, Mahadevappa Rampure Medical College,

Kalaburagi, Karnataka, India 
External fixation is a treatment option, primarily reserved for highly unstable and severely comminuted fractures. This technique relies on ligamentotaxis, which indirectly pulls the fracture fragments through longitudinal traction. External Fixation does not directly address the reduction and maintenance of the dorsal tilt or intra-articular fragments ${ }^{[14]}$.

Aim of the study was to know the surgical and functional outcome of distal radius fractures treated by external fixation.

\section{Material and Methods}

The present study includes 40 cases of distal radius fractures who had come to our hospital between Jan 2017 to Dec 2018. All the patients were operated with external fixation and final outcome was measured by Gartland and Werley Score (demerit system) ${ }^{[14]}$.

\section{Inclusion criteria}

- Age group $>14$ years

- Patients with distal radius fracture.

- Patient fit for surgery and willing to be treated with external fixation

\section{Exclusion criteria}

- Open fractures of distal end radius.

- Delayed presentation (>1week).

- Patients not willing for surgery

- Associated with ipsilateral forearm or hand fracture.

Written informed consent from the patients were obtained. Detailed history was taken from each of them and required investigations were done. $\mathrm{X}$ ray was considered mainstay for concluding the fracture type, site and the basis of further intervention and follow up. X-rays were taken in standard AP/Lateral views of wrist.

Postoperatively patients were followed at 4 weeks, 6 weeks, 3 months and 6 months.

Distal radius fractures were classified according to Frykman's ${ }^{[15]}$ system of classification

\section{Post-Operative Care and Rehabilitation}

Check X -rays were taken in both Antero-posterior and lateral views on first post-operative day. Confirmation of reduction of the fracture was done and any displacement of fracture was studied. Enough ligamentotaxis should be achieved by tension across the wrist generated by external fixation, so that on an Antero-posterior radiograph the radiocarpal articulation was seen to be $1 \mathrm{~mm}$ wider than the midcarpal joint postoperatively, the fixator remains in place for approximately 6 weeks. From the day of operation active exercises of fingers and thumb were commenced. Third post-operative day the dressing were removed. The pins were cleaned with spirit on every alternate day for one week; later the patient was educated regarding pin site care. Throughout the period of the healing the patients were thought exercises for the hand, pronation and supination of the forearm and active movement of the elbow and shoulder were advised. At 2 weeks after surgery, the sutures were removed. Wrist ROM was started after external fixator removal. Strengthening was initiated as ROM improved and normalizing of symptoms. The final functional outcome was measured by Gartland and Werley scoring system at 3 months follow up.

The system of Gartland and Werley demerit system ${ }^{14}$ is a mixed subjective and objective assessment that includes residual deformity ( 3 points), subjective evaluation (6 points), objective evaluation based on range of movement (5 points), and complications including pain (5 points). Points were added for the four categories and a final rating were obtained as follows With excellent being 0 to 2 , good 3 to 8 , fair 9 to 20 , and poor $\geq 21$.

\section{Results}

Among 40 patients who fulfilled inclusion criteria and were operated with external fixation, 24 were male and 16 were female. The mean patient age was 35 years (22yrs-50yrs). Left hand was involved in 26 patients and right hand in 14 patients. The mechanism of injury was road traffic accident in 30 patients followed by fall in 10 patients. Most of the patients were operated within 3-4 days of injury. 36 patients had intraarticular and 4 patients had extra articular fracture. 12 patients with high impact type injuries had associated fractures, 4 patient had fracture shaft of femur, 2 had fracture of both bones of leg, and 2 had fracture of the Right patella, 4 patients had head injury.

According to Frykman's classification of fractures, Out of 40 cases, 4 cases are of Type I fracture, 2 case of Type II, 8 cases of Type III, 16 cases of Type IV, 6 cases of Type V, no cases of Type VI and Type VII and 4 cases of Type VIII.

Patients were followed up at 4weeks, 6weeks, 12weeks and 6 months. Follow up x-rays were taken. External fixator removal done at 6weeks. Patients were evaluated clinically and radiologically for union. Clinical union described as no tenderness on clinical examination at old fracture site. Radiological union described as callus bridging or no fracture line after comparing the preoperative $\mathrm{x}$-ray with the latest follow up x-ray.

In our study, it reveals that, Out of $40(100 \%)$ patients treated with external fixation $38(86 \%)$ had dorsiflexion within the normal functional range (minimum $\left.45^{\circ}\right), 42(95 \%)$ had palmar flexion within the Normal functional range (minimum $30^{\circ}$ ), 40 (91\%) had pronation within the normal functional range (minimum $\left.50^{\circ}\right), 42(95 \%)$ had supination within the normal functional range (minimum50 $), 44(100 \%)$ had radial deviation within the normal functional range (minimum $15^{\circ}$ ) and $34(77 \%)$ patients had ulnar deviation within the normal functional range (minimum $15^{\circ}$ ). 36(82\%) patients had no pain at distal radioulnar joint, $34(77 \%)$ patients had grip strength more than $60 \%$ compared to the opposite side.(Table-1)

Subjective evaluation: Among 40 patients of external fixation 20 patients had excellent results, 12 patients had good results, 7 patients had fair results and 1 patients had poor results.(Table-2) Out of 40 patients in external fixation, $12(30 \%)$ patients had pin tract infection and $10(25 \%)$ patients had pin loosening which subsided with oral antibiotics.

End Results according to Gartland and Werley's score: Among 40(100\%) patients treated with External fixation the results were Excellent in 20(50\%) patients, Good in $12(30 \%)$ patients, Fair in $7(17 \%)$ patients, and Poor in $1(3 \%)$ patient. (table 3 )

Table 1: Range of motions

\begin{tabular}{|c|c|}
\hline Movements (within normal range) & $\begin{array}{c}\text { External fixation } \\
(\mathbf{2 2} \text { patients) }\end{array}$ \\
\hline Dorsiflexion $\left(\min 45^{0}\right)$ & $38(86 \%)$ \\
\hline Palmar flexion $\left(30^{0}\right)$ & $42(95 \%)$ \\
\hline Pronation $\left(50^{0}\right)$ & $40(91 \%)$ \\
\hline Supination $\left(50^{0}\right)$ & $42(95 \%)$ \\
\hline Radial deviation $\left(15^{0}\right)$ & $44(100 \%)$ \\
\hline Ulnar deviation $\left(15^{0}\right)$ & $34(77 \%)$ \\
\hline Pain at radioulnar joint & $36(82 \%)$ \\
\hline Grip strength(60\% or less than on opposite side) & $34(77 \%)$ \\
\hline
\end{tabular}


Table 2: Subjective evaluation

\begin{tabular}{|c|c|}
\hline Subjective evaluation & External fixation (out of 40 patients) \\
\hline Excellent & 20 \\
\hline Good & 12 \\
\hline Fair & 07 \\
\hline Poor & 01 \\
\hline
\end{tabular}

Table 3: End result according to Gartland and Werley's score

\begin{tabular}{|c|c|}
\hline End Result & No. of patients \\
\hline Excellent $(0-2)$ & 20 \\
\hline Good $(3-8)$ & 12 \\
\hline Fair(9-20) & 7 \\
\hline Poor $(>21)$ & 1 \\
\hline
\end{tabular}
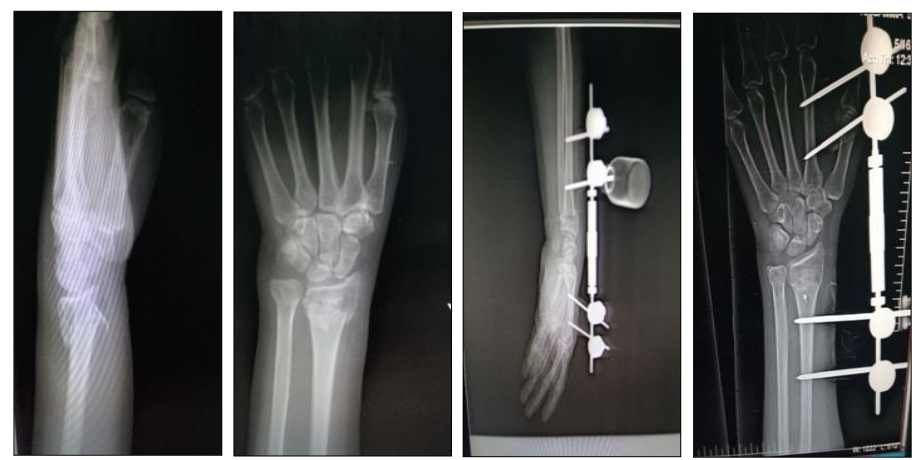

Image 1: Pre-op x-ray AP and lateral: Post-op AP and lateral
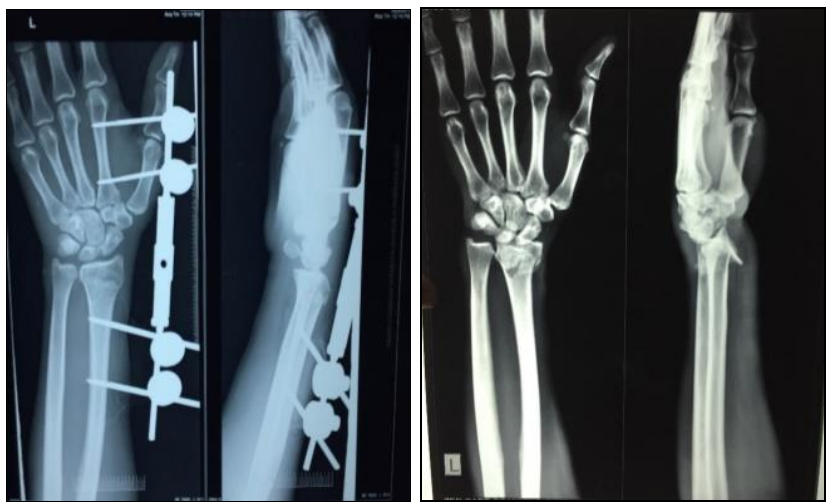

Image 2: Pre-op x-ray AP and lateral Post-op AP and lateral

\section{Discussions}

In a prospective randomized study, Roumen et al compared EF with closed reduction and immobilization for displaced distal radial fractures in older patients. Patients treated with External fixation had significantly better radiological results while the functional results did not show any difference ${ }^{[16]}$.

Atroshi et al compared in a randomized study, the two different methods of external fixation in a cohort of elderly patients. A better radial length at 1 year in the non-bridging group was seen but there was no significant differences in functional results of both groups. Aketin et al described similar findings in a retrospective study with patients older than 65 years ${ }^{[17]}$.

In our study significant number of patients had good to excellent final functional outcome.

In a study done by Cooney et al. the end results were excellent in $38 \%$ patients, good in $55 \%$ and fair in $13 \%{ }^{[18]}$.

Sanders et al.1991. Found end results according to gartland and werley's score as excellent in 34\% patients, good in $34 \%$ patients, fair in $29 \%$ patients and poor in $3 \%$ patients ${ }^{[19]}$.

To study the management of distal end radius fracture by utilizing the principle of ligamentotaxis as conducted by
Chilakamary VK et al, it was concluded that external fixator was an effective method of treating unstable extra articular and complex intra articular fractures. Improved anatomical restoration along with early rehabilitation produced favorable functional outcome ${ }^{[20]}$.

Complications associated with EF are pin-tract infection, iatrogenic lesion of the superficial radial nerve. Complex regional pain syndrome (CRPS) may result due to overdistraction of the wrist joint. Usually the external fixation is applied for 6 week especially to osteoporotic bone with weak hold of the pins. Loosening of the pins may occur so they have to be removed before definitive bone healing. In our study, no neurovascular complications were reported. 12 patients had pin tract infection and 10 patients had pin loosening which subsided with oral antibiotics.

The Roger-Andersen device used by Grana WA, Kopta JA ${ }^{[21]}$ in the treatment of distal radius fractures had $80 \%$ excellent and good results. They felt that 4 pins gave better fixation and pin loosening was less when compared with 2 pins, results were in comparison with our study.

Cooney WP et al. analysed the results with four different external fixation devices in a consecutive series of 100 unstable distal radial end fractures and opined that quadrilateral frame fixation provided effective immobilization and produced good to excellent results in $86 \%$ of patients ${ }^{[2]}$.

In another Prospective study in Indian rural set-up done by Pinnamaneni $\mathrm{S}$ et al, it was concluded that external fixation can be considered as effective treatment in elderly populations of Indian rural set up as it is a simple and cost effective procedure with good results ${ }^{[23]}$.

\section{Conclusion}

Our study concluded that external fixation as a treatment modality for displaced distal end radius fractures proves to be minimally invasive. The risk of neurovascular damage also runs low with this mode of treatment. The removal of hardware post healing of fracture is easy. The patients also tend to be compliant. The patients could quickly switch to their daily normal routine. Hence it is a good treatment option for any age group of patients with excellent to good functional outcome.

\section{References}

1. Reis FB, Faloppa F, Saone RP, Boni JR, Corvelo MC. Fraturas do terço distal do rádio: classificação e tratamento. Rev Bras Ortop. 1994; 29(5):326-330.

2. Arora R, Gabl M, Gschwentner M, Deml C, Krappinger D, Lutz M. A comparative study of clinical and radiologic outcomes of unstable colles type distal radius fractures in patients older than 70 years: nonoperative treatment versus volar locking plating. J Orthop Trauma. 2009; 23(4):237242.

3. O'Neill TW, Cooper C, Finn JD, Lunt M, Purdie D, Reid DM. Incidence of distal forearm fracture in British men and women. Osteoporos Int. 2001; 12(7):555-558

4. McQueen MM, Hajducka C, Court-Brown CM. Redisplaced unstable fractures of the distal radius: A prospective randomised comparison of four methods of treatment. J Bone Joint Surg Br. 1996; 78(3):404-409.

5. Liporace FA, Adams MR, Capo JT, Koval KJ. Distal radius fractures. J Orthop Trauma. 2009; 23(10):739-748.

6. McCall TA, Conrad B, Badman B, Wright T. Volar versus dorsal fixed-angle fixation of dorsally unstable extraarticular distal radius fractures: A biomechanic study. J 
Hand Surg Am. 2007; 32(6):806-812.

7. Kapandji A. [Internal fixation by double intrafocal plate. Functional treatment of non-articular fractures of the lower end of the radius (author's transl)] Ann Chir. 1976; 30(1112):903-908.

8. Ring D, Jupiter JB, Brennwald J, Büchler U, Hastings H. 2nd Prospective multicenter trial of a plate for dorsal fixation of distal radius fractures. J Hand Surg Am. 1997; 22(5):777-784.

9. Osada D, Viegas SF, Shah MA, Morris RP, Patterson RM. Comparison of different distal radius dorsal and volar fracture fixation plates: A biomechanical study. J Hand Surg Am. 2003; 28(1):94-104.

10. Wong KK, Chan KW, Kwok TK, Mak KH. Volar fixation of dorsally displaced distal radial fracture using locking compression plate. J Orthop Surg (Hong Kong) 2005; 13(2):153-157.

11. Lorich DG, Gardner MJ. Placas. In: Rüedi TP, Buckley RE, Moran CG, editors. Principios AO do tratamento de fraturas. Tradução de Jacques Vissoky. 2a. ed. Artmed; Porto Alegre, 2009.

12. Arora R, Lutz M, Hennerbichler A, Krappinger D, Espen D, Gabl M. Complications following internal fixation of unstable distal radius fracture with a palmar locking-plate. J Orthop Trauma. 2007; 21(5):316-322.

13. Orbay JL, Fernandez DL. Volar fixation for dorsally displaced fractures of the distal radius: a preliminary report. J Hand Surg Am. 2002; 27(2):205-215.

14. Gartland JJ Jr, Werley CW. Evaluation of healed Colles' fracture. J Bone Joint Surg Am. 1951; 33:895-907.

15. Frykman G. Fracture of the distal radius including sequelaeshoulder-hand-finger syndrome, disturbance in the distal radio-ulnar joint and impairment of nerve function. A clinical and experimental study. Acta Orthop Scand. 1967; 108:3.

16. Roumen RM, Hesp WL, Bruggink ED. Unstable Colles' fractures in elderly patients. A randomised trial of external fixation for redisplacement. J Bone Joint Surg Br. 1991; 73(2):307-311.

17. Aktekin CN, Altay M, Gursoy Z, Aktekin LA, Ozturk AM, Tabak AY. Comparison between external fixation and cast treatment in the management of distal radius fractures in patients aged 65 years and older. J Hand Surg Am. 2010; 35(5):736-742.

18. Cooney WP III. Fractures of distal radius: A modern treatment - based classification - Distal Radius fractures. Orthop Clin N-Am, 1993; 24(2):211-216.

19. Sanders RA et al. External fixation of distal radial fractures: results and complication. J Hand Surg Am. 1991; 16(3):385-91.

20. Chilakamary VK, Lakkireddy M, Koppolu KK, Rapur S. Osteosynthesis in Distal Radius Fractures with Conventional Bridging External Fixator; Tips and Tricks for Getting Them Right. J Clin Diagn Res, 2016.

21. Grana WA, Kopta JA. The Roger Anderson device in the treatment of fractures of the distal end of radius. J Bone Joint Surg [Am]. 1979; 61(A):12-34.

22. Cooney WP. External fixation of distal radius fractures. Clin Orthop. 1983; 180:44-49.

23. Dr. Sankara Rao Pinnamaneni, Dr. Srikanth Choppara, Dr. Saurabh Deshpande, Dr. Manjeera R. Prospective study of unstable distal radius fractures treated with external fixation in Indian rural set-up, International Journal of Orthopaedics 